\title{
ADSORÇÃO DE ÁCIDO ACÉTICO EM CARVÃO ATIVADO PARA O ENSINO DE ADSORÇÃO
}

\section{ACETIC ACID ADSORPTION IN ACTIVATED CARBON FOR ADSORPTION TEACHING}

\author{
B. J. A. GONÇALVES and K. C. S. FIGUEIREDO*
}

Federal University of Minas Gerais, Department of Chemical Engineering, Belo Horizonte, Minas Gerais, Brazil

${ }^{*}$ Corresponding author. Federal University of Minas Gerais, Department of Chemical Engineering, Belo Horizonte, Minas Gerais, Brazil, Phone: +553134091781 e-mail address: katia@deq.ufmg.br (K.C.S. Figueiredo).

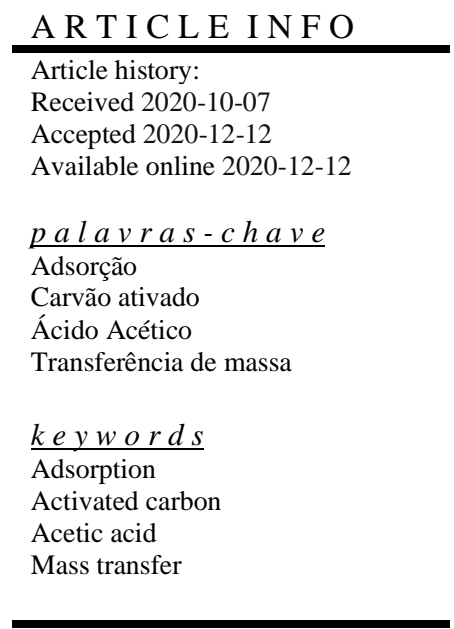

\begin{abstract}
A B S T R A C T
Adsorption is a phenomenon in which the enrichment of a substance occurs at an interface, and at least one phase must be condensed. It is a spontaneous process that occurs due to imbalance offorces on the surface. It has wide application in the industry, such as purification of liquids, gases and even in the field of medicine. This work presents a simple adsorption experiment of acetic acid in activated carbon, suitable for teaching concepts involved in mass transfer classes. Data were adjusted to the Langmuir isotherm and important topics from the process and model were discussed.
\end{abstract}

R E S U M O

Adsorção é um fenômeno em que ocorre o enriquecimento de uma substância numa interface, sendo que pelo menos uma fase deve ser condensada. É um processo espontâneo que ocorre devido ao desbalanceamento de forças na superfície. Tem vasta aplicação na indústria, desde purificação de líquidos, gases e até no campo da medicina. Este trabalho apresenta um experimento simples de adsorção de ácido acético em carvão ativado, apropriado para o ensino dos conceitos envolvidos em aulas de transferência de massa. Os dados obtidos foram ajustados na isoterma de Langmuir, e os pontos importantes do processo e do modelo foram discutidos. 


\section{INTRODUCTION}

Adsorção é basicamente a acumulação de uma substância em uma interface. $\mathrm{Na}$ adsorção, as partículas presentes numa fase fluida são atraídas para a zona interfacial, como a superfície de um sólido, por exemplo, devido à existência de forças atrativas não compensadas na superfície do material. Para que ocorra a compensação destas forças, os sólidos ou líquidos retêm em suas superfícies gases, vapores ou outras substâncias dissolvidas (BUTT et al., 2003, FREITAS, 2005, ABDEHAGH et al., 2014).

A substância aderida à superfície é chamada de adsorvato, enquanto aquele material capaz de reter partículas em sua superfície é o adsorvente. Em geral, pode-se considerar dois tipos principais de adsorção: física e química.

A adsorção física normalmente está relacionada a forças de van der Waals, ou seja, é uma interação mais fraca, em que não há sítios específicos de ligação e não envolve compartilhamento ou transferência de elétrons. É um fenômeno reversível, apresentando energias da ordem de $20-40 \mathrm{~kJ} / \mathrm{mol}$. Este fenômeno pode ocorrer sucessivamente com a formação de várias camadas de adsorvato (BUTT et al., 2003).

A adsorção química envolve compartilhamento ou transferência de elétrons, e o adsorvato encontra-se fortemente ligado ao adsorvente, não apresentando mobilidade. Normalmente, ocorre a formação de apenas uma camada e as energias envolvidas são da ordem de 100-400 kJ/mol (BUTT et al., 2003).

A adsorção é um processo energeticamente favorável, e possui várias aplicações na indústria, como processo de separação de compostos orgânicos da água, remoção de corantes (GHAEDI et al., 2017), purificação de $\mathrm{CO}_{2}$ do ar, separação de combustíveis e até remoção de agentes patogênicos do sangue (MATSUO, 2017). Em muitas destas aplicações, considera-se a adsorção em sólidos, ou seja, partículas de um líquido são adsorvidas na superfície de um sólido, resultando na purificação ou concentração de uma solução, seja líquida ou gasosa.

A quantidade de adsorvato que é capaz de aderir em um determinado adsorvente é regido pelo equilíbrio entre as fases. Para um sistema simples, é possível construir uma curva de concentração do soluto na fase sólida em função de concentração do soluto na fase fluida. Esse tipo de curva depende da temperatura e é chamada de isoterma de adsorção. São observados vários formatos de isotermas, para os quais mecanismos e equações são propostos. Uma isoterma simples com base teórica e aplicação em adsorção para superfícies homogêneas com pouca interação entre as moléculas de adsorvato é a isoterma de Langmuir (FREITAS, 2005; BUTT et al., 2003; CASTELLAN, 1995).

A isoterma de Langmuir considera algumas hipóteses:

- As moléculas são adsorvidas em pontos discretos da superfície que são chamados "sítios de adsorção".

- A energia de uma espécie adsorvida é a mesma em qualquer ponto da superfície e independe de moléculas adsorvidas na vizinhança.

- Considera-se apenas a formação de uma monocamada.

- A adsorção é localizada e ocorre por colisão de moléculas com sítios vazios.

Se considerarmos a adsorção como reação química entre um adsorvato gasoso " $\mathrm{A}$ " e o adsorvente, temos:

$$
\mathrm{A}(\mathrm{g})+\mathrm{B} \rightleftarrows \mathrm{AB}
$$

$B$ refere-se a um sítio vazio no adsorvente, e AB representa uma molécula adsorvida ou um espaço ocupado. Assim sendo, podemos assumir que a constante de equilíbrio, $\mathrm{K}$, pode ser representada pela equação 2 :

$$
K=\frac{x_{A S}}{x_{S} p}
$$

Em que " $\mathrm{x}_{\mathrm{AS}}$ " representa a fração de espaços ocupados, " $x_{\mathrm{S}}$ " a fração de espaços livres e "p" a pressão do gás. Usualmente o termo " $\mathrm{x}_{\mathrm{AS}}$ " é representado por $\Theta$ e " $\mathrm{x}_{\mathrm{s}}$ " por 1 $\Theta$. Substituindo e resolvendo para $\Theta$, temos a equação 3 , que é a expressão para a isoterma de Langmuir:

$$
\theta=\frac{K p}{1+K p}
$$

Caso a adsorção esteja ocorrendo em uma solução, substitui-se o termo p por "c" indicando a concentração molar. Assim sendo, a quantidade de substância adsorvida "m", será proporcional à fração de espaços ocupados que chamamos de $\Theta$, logo podemos relacionar os termos através de uma constante, sendo $\mathrm{m}=\mathrm{b} \theta$.

Substituindo $\Theta$, temos as equações 4 e 5 :

$$
\mathrm{m}=\frac{b K p}{1+K p}
$$

ou

$$
\mathrm{m}=\frac{b K c}{1+K c}
$$

Rearranjando, obtém-se a equação 6:

$$
\frac{1}{\mathrm{~m}}=\frac{1}{b}+\frac{1}{b K c}
$$

Ao construir o gráfico de $1 / \mathrm{m}$ versus $1 / \mathrm{c}$, é possível determinar as constantes b e $\mathrm{K}$ através dos coeficientes linear e angular fornecidos pela reta observada. Conhecendo o valor de $\mathrm{K}$, basta voltar à equação 2 para obter o valor correspondente à fração de espaços ocupados. Esta isoterma foi desenvolvida para utilização em sistemas sólido gás, mas também adequa-se a sistemas sólido-líquido, desde que em soluções diluídas (CASTELLAN, 1995).

A isoterma de Freundlich considera a fisissorção das espécies em multicamadas sobre o adsorvente. O modelo é empírico, representado pelas equações 7 e 8 , este último na forma linearizada, onde k e n são constantes do modelo. 


$$
m=k c^{\frac{1}{n}}
$$

$$
\log m=\log k+n \log c
$$

Este artigo descreve um experimento simples para verificar a adsorção do ácido acético no carvão ativado, a fim de permitir ao estudante o contato com o processo de adsorção, e a verificação do ajuste do modelo teórico à uma situação prática em que ocorre o fenômeno.

\section{MATERIAIS E MÉTODOS}

Foram utilizados carvão ativado (Merck), ácido acético glacial (Sigma-Aldrich) e $\mathrm{NaOH}$ P.A. (Dinamica).

Antes do início da prática, o carvão ativado comercial foi seco por 2 horas a $95^{\circ} \mathrm{C}$. Cerca de $1 \mathrm{~g}$ do carvão foi transferido para cada um de seis erlenmeyers de $250 \mathrm{~mL}$ em seguida, sendo que a massa pesada foi anotada em cada erlenmeyer. É importante realizar a pesagem do carvão o mais rapidamente possível, pois o contato do mesmo com o ar permite que a umidade seja adsorvida pelo carvão, prejudicando o estudo posteriormente. Após a pesagem, os erlenmeyers foram devidamente tampados com plástico filme ou similar até o momento da prática.

Durante a prática, a partir de uma solução estoque de 1 $\mathrm{mol} / \mathrm{L}$ de ácido acético em água, foram preparadas soluções com seis diferentes concentrações diluindo-se respectivamente 1,2 ,5, 10, 15 e $25 \mathrm{~mL}$ em balões de $50 \mathrm{~mL}$. Cada uma das soluções $(50 \mathrm{~mL})$ foi transferida para um frasco erlenmeyer contendo aproximadamente $1 \mathrm{~g}$ de carvão ativado. Os frascos foram tampados e permitiu-se o contato durante 30 minutos, durante os quais os frascos foram agitados a cada 5 minutos. Este tempo é suficiente para que seja atingido o equilíbrio, e a agitação garante o contato de toda a superfície do carvão com a solução, conforme observado em teste cinético prévio.

Enquanto ocorre o processo de adsorção, deve-se determinar a concentração exata da solução estoque, $\mathrm{C}_{\mathrm{e}}$. Para isso, foi feita a titulação de $5 \mathrm{~mL}$ da solução estoque contra uma solução padronizada de $\mathrm{NaOH} 1$ mol.L $\mathrm{L}^{-1}$, utilizando fenoftaleína $1 \% \mathrm{v} / \mathrm{v}$ como marcador, em triplicata. Com o valor obtido, calculou-se as concentrações das 6 soluções utilizadas.

Após 30 minutos, as soluções foram separadamente filtradas de maneira simples, utilizando apenas papel de filtro qualitativo e um funil de vidro. O carvão comercial possibilita uma filtração rápida mesmo sem o uso de bomba de vácuo.

Em seguida, determinou-se a concentração de equilíbrio das soluções através de titulação contra uma solução de $\mathrm{NaOH}$ 0,1 mol. $\mathrm{L}^{-1}$. Todas as titulações foram feitas em triplicata. As 3 soluções mais diluídas foram tituladas tomando-se alíquotas de $10 \mathrm{~mL}$, e as 3 soluções mais concentradas com alíquotas de 2 $\mathrm{mL}$ apenas. Essas quantidades foram escolhidas a fim de que as titulações fossem realizadas com volumes adequados ao tempo e equipamento utilizados. Todo o procedimento foi realizado na temperatura de $298 \mathrm{~K}$. O cálculo das concentrações de equilíbrio, $\mathrm{C}_{\mathrm{eq}}$, foi realizado pelo produto do volume médio de titulante pela concentração de $\mathrm{NaOH}$ exata da solução.

Os dados obtidos foram linearizados via Excel, conforme a Equação 6. A quantidade adsorvida foi calculada pela diferença correspondente à parcela adsorvida, conforme equação 9 , onde $C_{0}$ e $C_{\text {eq }}$ são as concentrações inicial e de equilíbrio de ácido acético, $\mathrm{V}$ é o volume da solução e $\mathrm{m}_{\mathrm{ads}}$ é a massa de adsorvente adicionada ao sistema.

$$
\mathrm{m}=\frac{\left(C_{0}-C_{e q}\right) V}{m_{a d s}}
$$

$\mathrm{O}$ valor de $\mathrm{C}_{0}$ foi calculado a partir do produto entre a concentração da solução estoque e o fator de diluição de cada uma das seis soluções diluídas de ácido acético preparadas no início do experimento.

\section{RESULTADOS E DISCUSSÃO}

Em geral, espera-se que a concentração de ácido medida ao final do experimento seja menor do que aquela calculada inicialmente e que a quantidade seja maior para as soluções mais concentradas. Fontes de erro neste experimento podem ser devido à exposição prolongada do carvão ao ambiente, reduzindo a quantidade de sítios de adsorção ocupados. Os dados da adsorção foram apresentados na Tabela 1 e o ajuste da isoterma na Figura 1.

\section{Tabela 1 - Dados de adsorção do ácido acético em carvão} ativado a $298 \mathrm{~K}$.

\begin{tabular}{ccc}
$\mathbf{C}_{\mathbf{0}}\left(\mathbf{g} \cdot \mathbf{L}^{-1}\right)$ & $\mathbf{C}_{\text {eq }}\left(\mathbf{g} \cdot \mathbf{L}^{-1}\right)$ & $\mathbf{m}\left(\mathbf{m g} \cdot \mathbf{g}^{-1}\right)$ \\
1,18 & 1,05 & 6,71 \\
2,37 & 2,12 & 12,47 \\
5,92 & 5,11 & 40,23 \\
11,83 & 10,68 & 57,57 \\
17,75 & 16,02 & 86,36 \\
\hline 29,58 & 27,36 & 110,55 \\
\hline
\end{tabular}

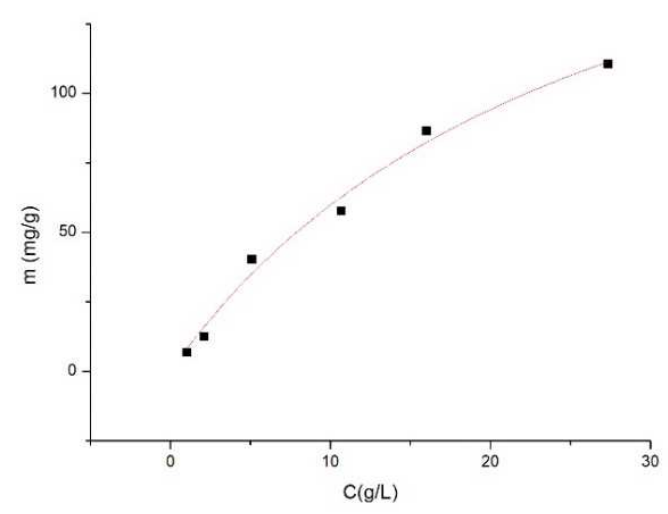

Figura 1 - Ajuste da isoterma de Langumuir de adsorção do ácido acético em carvão ativado.

Para o ajuste ajuste obtido, o valor do coeficiente de correlação $\mathrm{R}^{2}$ foi de 0,987 , indicando que o fenômeno de adsorção entre o ácido acético e o carvão ativado provavelmente ocorrem como descrito por Langmuir, considerando a presença de apenas uma monocamada na superfície do carvão, adsorção do tipo química, com pouquíssima interação entre os sítios.

Como demonstrado nas equações 4 e 5 , os valores $\mathrm{k}$ e b são fornecidos pelos parâmetros das equações 4 para gases e 5 para soluções líquidas. Os valores das constantes $\mathrm{K}$ e b para os dados fornecidos foram apresentados na Tabela 2. 
Tabela 2 - Valores das constantes para a Isoterma de Langmuir

\begin{tabular}{c|c}
\hline Constante & Valor \\
\hline K & $\mathbf{0 , 0 3 7}$ \\
\hline b & $\mathbf{2 2 1 , 5 0 6}$ \\
\hline
\end{tabular}

O valor da constante $b$, que correspondente ao limite da adsorção em monocamada, bem como os valores de adsorção presentes na curva apresentada condizem com os valores observados na literatura. Zhang e colaboradores apresentaram dados de um carvão ativado de casca de coco para remoção de ácido acético de soluções diluídas. A quantidade adsorvida de ácido acético (m) medida foi de $158 \mathrm{mg} \cdot \mathrm{g}^{-1}$, para uma concentração inicial de 31,68 g.L. $\mathrm{L}^{-1}$, semelhante ao valor encontrado neste trabalho, que foi de $110,55 \mathrm{mg} \cdot \mathrm{g}^{-1}$ para concentração inicial de 29,58 g.L. . $^{-1}$ O carvão também se comportou melhor do que alguns tipos de zeólitas, que exibiram valores entre 78 e $89 \mathrm{mg}^{-g^{-1}}$, nas mesmas condições (ZHANG et al., 2015).

O modelo da isoterma de Langmuir é importante pois descreve o fenômeno de adsorção com um embasamento teórico, fornecendo importantes dados sobre o fenômeno analisado. Quando ocorre adsorção em multicamada, o ajuste na isoterma de Langmuir não é satisfatório, exigindo o uso de modelos matematicamente mais elaborados, que, no entanto, não possuem o embasamento teórico visto no primeiro.

O ajuste para a isoterma de Freundlich é apresentado na Figura 2, com coeficiente de correlação $\mathrm{R}^{2}$ igual a 0,975 . Os valores constantes k e n são apresentados na Tabela 3. Para esta isoterma, o valor de k está relacionado à capacidade de adsorção e o valor de $\mathrm{n}$ diz respeito à intensidade da adsorção. Valores mais baixos de $n$, mais próximos da unidade, indicam adsorção menos favorável. A isoterma de Freundlich, no entanto, prevê de forma mais adequada sistemas em que se observa a adsorção física, com a formação de várias camadas de adsorvato, em que a ligação com o adsorvente é mais fraca.

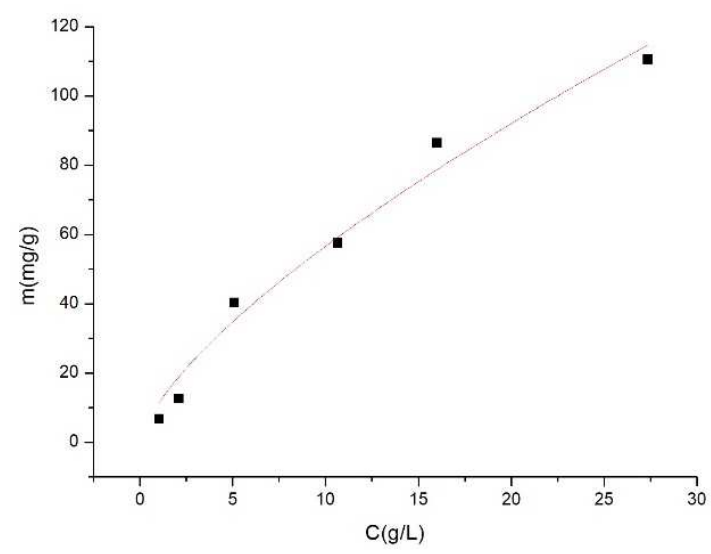

Figura 2 - Ajuste da isoterma de Freundlich de adsorção do ácido acético em carvão ativado

Como pode ser observado, o coeficiente de correlação para o ajuste da isoterma de Freundlich é menor do que o para a isoterma de Langmuir, indicando que a adsorção é do tipo química em monocamada.
Tabela 3 - Valores das constantes para a Isoterma de Freundlich

\begin{tabular}{c|c} 
Constante & Valor \\
\hline $\mathbf{k}$ & $\mathbf{1 1 , 2 6}$ \\
\hline $\mathbf{n}$ & $\mathbf{1 , 4 3}$ \\
\hline
\end{tabular}

A observação dos dados indica que o carvão ativado é um bom adsorvente para o ácido acético, e o fenômeno se caracteriza como adsorção química em monocamada, como indicado pelo ajuste com a isoterma de Langmuir. É importante observar que uma característica importante para um bom adsorvente é a área superficial, que está diretamente relacionada com a capacidade de adsorção do material. Bons adsorventes, como o carvão ativado, podem apresentar áreas superficiais da ordem de até 1000 metros quadrados. A granulometria do material também é um fator importante. Na literatura se observa aumentos de mais de $30 \%$ no valor de adsorvato por grama de adsorvente comparando o mesmo material granulado e em pó (ZHANG et al., 2015).

Uma das aplicações possíveis deste processo é na remoção de poluentes de águas utilizando carvão ativado para adsorção. Moléculas orgânicas de massas molares relativamente pequenas, semelhantes ao ácido acético, corantes ou outros poluentes podem ser removidos de águas residuárias de processo utilizando a adsorção em batelada ou em colunas de recheio contendo carvão. Estas aplicações ilustram um processo simples e relativamente barato para a produção de água para reúso.

\section{CONCLUSÃO}

Os dados coletados no processo de adsorção do ácido acético em carvão ativado mostraram um bom ajuste com o modelo da Isoterma de Langmuir. Dessa forma, é possível obter a fração de espaços ocupados no adsorvente, bem como caracterizar o tipo de adsorção, no caso em monocamada, o que revela muito sobre o processo. Outros modelos empíricos podem ser utilizados, como a Isoterma de Freundlich, embora mesmo com um ajuste adequado não haja embasamento teórico direto que dê significado direto aos valores obtidos.

\section{R E F E R Ê N C I A S}

ABDEHAGH, N., TEZEL, F. H., THIBAULT, J. Adsorbent screening for biobutanol separation by adsorption: kinetics, isotherms and competitive effect of other compounds. Adsorption, v. 19, p. 1263-1272, ago. 2013.

BUTT, H., GRAF, K., KAPPL, M. Physics and Chemistry of Interfaces. $1^{\mathrm{a}}$ ed., Weinheim, Baden-Württemberg, Germany: WILEY- n Verlag GmbH \& Co. KGaA, 2003.

CASTELLAN, G. Fundamentos de Físico-Química. $1^{\mathrm{a}}$ ed. (reimpressão), São Paulo: LTC, 1995.

FREITAS, A. F. Estudo da adsorção de ácidos Carboxílicos em Diferentes Materiais Adsorventes. 2005. $151 \mathrm{f}$. Dissertação (Mestrado em Engenharia Química) Universidade Federal Rural do Rio de Janeiro, Seropédica, RJ, 2005.

GHAEDI, A. M., VAFAEI, A. Applications of artificial neural networks for adsorption removal of dyes from aqueous 
solution: A review. Advances in Colloid and Interface Science, v.245, p.20-39, abr. 2017.

MATSUO, H. The art of separation and adsorption: Historical review of apheresis in Japan. Transfusion and Apheresis Science, v. 56, p.646-648, out. 2017.

ZHANG, H., WANG, Y., BAI, P., GUO, X., NI, X. Adsorptive
Separation of Acetic Acid from Dilute Aqueous Solutions: Adsorption Kinetic, Isotherms, and Thermodynamic Studies. Journal of Chemical \& Engineering Data, v. 61, p. 213-219, nov. 2015. 